\title{
An Overview of New Delhi Metallo-Beta Lactamase-1 and Extended Spectrum Beta Lactamase Producing Bacteria: Need for an Alternate
}

\section{Chandar B, Pati S and Bhattacharya D*}

Department of Health Research (Govt. of India), ICMR-Regional Medical Research Centre, Chandrasekharpur, Bhubaneswar, India

*Corresponding author: Debdutta Bhattacharya, Scientist-C/Sr. Research Officer, ICMR-Regional Medical Research Centre, Dept. of Health Research, Govt. of India, Chandrasekharpur-751023, Bhubaneswar, India, Tel: +91-674-2305655; E-mail: drdebdutta.bhattacharya@yahoo.co.in

Received date: December 5, 2017; Accepted date: January 11, 2018; Published date: January 12, 2018

Copyright: ( 2018 Chandar B, et al. This is an open-access article distributed under the terms of the Creative Commons Attribution License, which permits unrestricted use, distribution, and reproduction in any medium, provided the original author and source are credited.

\begin{abstract}
Resistance to antibiotics is increasing dangerously worldwide. The emergence of antibiotic resistant bacteria is no more a local problem and calls for global action. It has become a leading challenge in infectious diseases management. The effectiveness of current drugs is restricted by emergence of multi-drug resistant bacterial strains and they have become the major reason for treatment failure of infections. Antimicrobial agents were initially highly successful in treating infections; however, their unsound use leads to rise in antimicrobial resistance frighteningly, especially in the developing countries. With the emergence of New Delhi Metallo-beta lactamase-1 and Extended Spectrum Beta Lactamase producing bacteria the clinicians are left with a very limited choice of treating the common infections. The recent situation calls for an urgent need for search of alternatives like herbal medicine which has shown potential in treating various other ailments. Because herbs are plants, they are often perceived as "natural" and therefore safe. Development of plant based compounds and combinational therapies using compounds may provide safer options for the community. Research should focus on scrutinizing compounds from plants for a target and bioactivity based drug discovery. However, the safety of using most herbs with drugs is not well established. Some herbs are known to interact with pharmaceutical drugs, although most of this information comes from case reports rather than systematic investigations. Because many herbs contain pharmacologically active compounds, some herbs may cause side effects through excessive biological effects. Unfortunately, the true frequency of side effects for most herbs is not known because most have not been tested in large clinical trials and because surveillance systems are much less extensive than those in place for pharmaceutical products. There is also a need for a strict regulations and policy in place for the use of herbal drugs or compounds of herbal origin in treatment of various common bacterial infections.
\end{abstract}

\section{Keywords:}

$$
\text { Multi-drug resistance, NDM-1, ESBL, Herbal drugs }
$$

\section{Introduction}

Overuse and misuse of antibiotics has led to rapid evolution of antibiotic resistance across the globe [1]. Consumption of antibiotics globally capita has increased by $70 \%$ within the last decade [2]. Antimicrobial resistance has evolved since the beginning of the antibiotic era causing a menace in 21 st century. A worldwide antimicrobial consumption in animals was $63151( \pm 1560)$ tons in 2010 and projected to rise by $67 \%$ by 2030 . This increase in antimicrobial resistance has resulted increase in the cost of treating infectious diseases [3]. Hospital infections, high prevalence of infectious diseases, inadequate public health systems, and easy access to inexpensive antibiotics without prescription together increase the resistance [4].

The microorganisms eventually become Multi-Drug Resistant (MDR) forms on continuous use of various antibiotics and become "superbugs". The "superbugs" are microbes with increased resistance due to several mutations that contain high levels of resistance to the many diseases [5]. Among the resistant pathogens the fast evolving gram negative bacteria include Acinetobacter sp., Citrobacter sp., Enterobacter sp., Klebsiella sp., P. aeruginosa, Escherichia coli, Nerisseria gonorrhoeae, Salmonella spp, Enterococcus faecium, Streptococcus pneumonia, Haemophilus influenza and Shigella spp including the Mycobacterium tuberculosis [6]. The modes of resistance in such bacterial species include altered target sites, specialized efflux pumps, DNA mutations that develop alternate metabolic pathways and production of enzymes that degrade antibiotics [7-9]. Resistance by the production of beta lactamase enzymes (ESBLs and Carbapenemases) has now become a threat around the world and WHO lists such bacteria in a critical priority category for the discovery of new drugs [6].

Carbapenems were the last line of treatment for most Extended Spectrum Beta Lactamase (ESBL) producing resistant organisms, however after the emergence of New Delhi Metallo-beta lactamase 1 (NDM-1) a recently evolved MBL has shown resistance to most classes of antibiotics including carbapenem except tigecycline, and colistin [10]. Demise for antibacterial drug discovery has been created after the discovery of a few NDM producing strains and gram-negative bacteria that are also resistant to colistin [11-13]. In this scenario, crisis for new antibiotics and untreatable infections prevail. Thus a significant impact in the discovery of alternative drugs from plant sources is a necessity as we are now in the "last resort" of antibiotics [14].

\section{Prevalence of ESBL and NDM-1}

Plasmid mediated beta lactamases that include metallo beta lactamses (MBLs) and Extended spectrum beta lactamases (ESBL) genes spread rapidly to different bacterial species, therefore, rapid modification of therapy, discovery of alternative drugs and initiation of infection control to prevent their dissemination are necessary [15].The 
extended spectrum beta-lactamases (ESBLs) including the PER VEB-1, BES-1, TEM and SHV-type beta-lactamases have the ability to hydrolyze penicillins, first, second and the third generation cephalosporins [16]. The ESBL producing bacteria are commonly also found to co-exist with Amp C, and CTX-M genes that makes such MDRs difficult to treat [17]. The carbapenems are still the first choice of treatment for serious infections associated with gram negative bacteria that includes $\beta$ - lactamase and ESBL-producing organisms $[18,19]$. ESBL-producing organisms were first detected in Europe and eventually reported in the other parts of the world [16,20]. Although the exact global prevalence of ESBL producing organisms is not known, certain studies in the Indian subcontinent have found nearly $50 \%$ prevalence $[21,22]$.

Resistance to carbapenem is however observed recurrently among gram-negative bacteria that involves production of MBLs. New Delhi Metallo-beta lactamase 1 (NDM-1) first discovered in a Swedish patient in 2008, had an alarming impact globally and bought the discovery of antibiotics to a halt. NDM producers were found to coexist with blaOXA genes [23,24], rmtC [25], rmtF [26] genes that brings down the treatment options. This threat further increased when the emergence of colistin resistant NDM producing bacteria was reported [13]. The novel NDM-1 not highly identical to other MBLs and is closely associated to VIM-1/VIM-2, with around $32.4 \%$ identity [27]. The major dissemination of NDM-1 producers were found in the Asian continent distributed mostly in China and India with around $58.15 \%$ abundance [28].The ESBLs and NDM-1 enzyme vary structurally the former having a serine within the active site while the latter two zinc ions within its active site respectively $[29,30]$. This alters the treatment regimens and strategies which in turn increases the demand for varied development perspectives for new antimicrobials $[18,28,31]$.

\section{Detection of antibiotic resistance for ESBL and NDM-1 producers}

Detection of resistance for these rapidly evolving microorganisms is an essential factor for the specific treatments. The assays such as double disk synergy test (DDST) or the Etest are used to determine the production of these beta-lactam enzymes [32]. DNA sequencing of the amplified PCR products from the isolates that carries these genes are purified using the PCR DNA purification kit and subjected to automated DNA sequencing. Susceptibility to various classes of antibiotics can be determined by disc diffusion method as prescribed by Clinical Laboratory Standard Institute (CLSI) guidelines is one of the most commonly used techniques to detect resistance. Apart from general tests, few specific tests are developed for ESBL and NDM-1. Presence of ESBL microorganisms are tested using Vitek2 ESBL test panel which analyses the synergy between ceftazidime, cefotaxime or cefepime and clavulanic acid. Few other tests are using EbSA ESBL screening agar, ChromID ESBL screening agar plates, and MIC-strip for ESBL and MicroScan panels $[33,16]$.

A TaqMan chemistry has been developed to detect NDM-1 carbapenemase genes from bacterial isolates and directly from stool samples using a quantitative real-time PCR (qPCR) assay [34]. CHROMagar KPC culture medium was proposed for an outbreak of NDM-1 for early detection of NDM-1 producers for any hospitalized patients on a worldwide scale and for at-risk patients in areas of where it may prevent outbreaks of NDM-1 producing infections [35]. Loop Mediated Isothermal Amplification (LAMP), for detecting blaNDM-1 gene in NDM-1 positive bacteria was developed which was a rapid non-culturable method [36,37]. A electrochemical biosensor was developed to detect blaNDM-1 gene encoding the NDM-1 enzyme, using label-free electrochemical impedance spectroscopy (EIS). In this EIS assay, they have used a blaNDM-specific PNA probe that was designed by applying a strategy that combines in-silico probe design and DNA microarray (fluorescence-based) validation with electrochemical testing using gold electrodes [38]. The membrane attachment of $\beta$-lactamases includes detection of carbapenemase activity by the MHT and a new method developed showed that this problem can be rectified by the addition of Triton X-100, called the Triton Hodge test, which allows detection of membrane-bound carbapenemases [39]. DiaPlexC CRE Detection Kit was made to detect 4 kinds of CRE genes, IMP, VIM, KPC and NDM using the Multiplex PCR. This can detect multiple specific target genes in a single PCR. NDM-1 ELISA kits are highly sensitive, and specific diagnostic assay for detection of blaNDM-1 based on cross priming amplification (CPA) was developed. The results showed that the CPA could detect as low as 2 copies of plasmid DNA, being more sensitive than PCR as well as LAMP [40].

\section{Treatment options}

Extensive efforts are taken to design multiple strategies to combat multidrug resistance and so far very little have been achieved. ESBLs frequently associated with genes encoding resistance to aminoglycosides and trimethioprim/sulfamethoxazole along with cephalosporin resistance. Clavulanic acid reduces the minimum inhibitory concentrations (MICs) of cephalosporins when treated against the ESBLs. Although carbapenems are not used as a first line of treatment for the ESBL-producing organisms they are mostly used against serious infections, due to their stability to withstand hydrolysis by ESBLs [41]. NDM-1 is resistant to all the antibiotics including $\beta$ lactam antibiotics only a few promising compounds have been reported so far to combact its resistance. Aspergillomarasmine-A (AMA), a natural compound from Aspergillus versicolor, was reported to inhibit NDM-1 activity by extracting zinc ions from its active site. AMA was able to fully restore the antibacterial activity of meropenem against NDM-1 harboring bacteria from Enterobacteriaceae, Acinetobacter spp. and Pseudomonas spp. [42]. Ebselen was shown to covalently bind with the Cys residue at the active site of NDM-1, thereby, offering a new inhibition mechanism with a potential broad spectrum inhibitory activity [43]. D-captopril binds to the active site of recombinant NDM-1 with high binding affinity, and inhibits its enzymatic activity [44]. Two thiol-modifying compounds, pchloromecuribenzoate ( $\mathrm{p}-\mathrm{CMB})$ and nitroprusside were also reported to inhibit the activity of NDM-1. p-CMB inhibited NDM-1 by modifying the Cys residue in the active-site of the enzyme. However, mutating this residue to Asp did not affect the enzyme activity and it has become resistant to the inhibitor [45]. Thirteen synthetic diarylsubstituted azolylthioacetamides were found to inhibit the activity of the NDM-1 enzyme isolated from Aeromonas veroni [46]. Combinatorial Genetics En Masse (CombiGEM) strategy was employed to identify transcription factor combinations to enhance killing of bacteria by $\beta$-lactam drugs against resistant Escherichia coli NDM-1 strains [47]. CRISPR-Cas for genome-editing was also used to target and modify antibiotic resistant genes [48]. Khan et al. (2017) [49] has discovered five non-beta-lactam inhibitors through virtual screening and confirmed efficacy of these molecules using in vitro cell assays. 


\section{Need for alternate treatment}

This global emergence of multi-drug resistant (MDR) bacteria is increasingly limiting the effectiveness of current drugs and significantly causing treatment failure [50] and urges for an urgent call for search of alternate resources for combating this growing menace. Plants have been used for health and medical purposes for several thousands of years. WHO also stressed on reduction of antibiotic usage by applying alternative strategies. The number of higher plant species on earth is about 250,000 . It is estimated that 35,000 to 70,000 species have, at one time or another, been used in some cultures for medicinal purposes. A majority of the world's population in developing countries still relies on herbal medicines to meet its health needs. The use of medicinal plant extracts and studying their pharmacological properties can lead to the development of modern therapeutic agents. Medicinal plants are important sources for pharmaceutical manufacturing. Medicinal plants and herbal medicines account for a significant percentage of the pharmaceutical market. For example, in China, medicinal plants and their products had a $33.1 \%$ share of the pharmaceutical market in 1995. In Malaysia, the market for traditional medicine is estimated at about 1 billion Malaysia rinngit annually [51]. The plant compounds such as flavanoid family and anthocyanins could give more potential microbial-inhibitory compounds that selectively influence intestinal bacteria species. Plant based drugs have a long history of use and better patient tolerance. They are renewable sources, cheap, inexpensive and locally available in many developing countries [52]. The simplest bioactive phytochemicals have a single substituted phenolic ring called simple phenols and phenolic acids. Structures of quinones contain two ketone substitutions in their aromatic rings. Phenolic structures that contain one carbonyl group are flavonoids or flavones and flavonol consists of addition of one 3-hydroxyl group. Plants fighting against microbial infections synthesize such compounds. Tannins are a group of polymeric phenolic substances found in bark, wood, leaves, fruits, and roots of almost every plant [53]. Phenolics can act as metal chelators that increase their catalytic activity or reduce metal ions, thus increasing their ability to act as antioxidants [54]. Flavonoids are reported to possess several properties, including oestrogenic, anti-inflammatory, antimicrobial, enzyme inhibition, vascular, antiallergic and antitumour activity [55]. Maddox et al. [56] have shown that different subgroups of flavonoid compounds, including flavan-3-ol (catechin), flavanone (naringenin), flavonol glycoside (rutin), and flavonol aglycone (quercetin) showed antibacterial activity against Xylella fastidiosa. The results of antimicrobial activity of 17 phenolic compounds showed different bacterial species demonstrate different activity profiles against phenolics. Differences in sensitivity to one flavonoid were observed with various strains of the same bacterial species. The berry extracts tested showed inhibition mostly of Gram-negative but not Grampositive bacteria [57]. Diterpenes, such as ent-3-hydroxy-beyer-15ene-2-one and diosphenol 2 isolated from Spirostachys africana showed activity against many Gram positive and Gram negative microorganisms. The compound 3-acetyl aleuritolic acid was found to inhibit various gram negative pathogenic microorganisms including Salmonella typhi, V. cholera and $S$. dysentery [58]. Monoterpenes like menthol, thymol, and linalyl acetate inhibited both the gram-positive Staphylococcus aureus and the gram-negative Escherichia coli by their membrane-damaging activity, which was shown by measuring the release of trapped carboxyfluorescein from large unilamellar vesicles [59]. The lectins act on cells in many ways, such as mitogenic stimulation, agglutination and killing $[60,61]$. These peptides inhibit the microbial membrane by interfering in the formation of ion channels or competitively inhibit the attachment of microbial proteins to the receptors on membrane $[62,63]$. The most commonly used alkaloids medically are morphine, ephedrine, quinine, piperine etc. Their bioactivity and challenging structures led to various modes of activity profile. The alkaloids showed inhibitory effects against various gram negative and gram-positive microorganisms and also against many fungal species [64]. Numerous natural products from plants such as angusticornin $\mathrm{B}$, bartericin $\mathrm{A}$, 6-hydroxy-7-methoxyluteolin, madreporanone, stachytriol have exhibited antibacterial activity [65-67]. PYN6 isolated from this plant has shown activity against major classes of infectious bacteria including MRSA [68]. Terpenoids from Ocimum spp. [69,70], berberine from Berberis vulgaris [71], tannin and terpenoids from Eucalyptus globules [72], $\beta$-Resercyclic acid an organic acid from Cannabis sativa [73] and flavonoid like quercetin and phenolic acid like caffeic acids from Camellia sinensis [74] are some antibacterial compounds isolated from plants. Phenolics such as flavonoids and tannins act in membrane disruption, enzyme inactivation and metal ion complexation. Terpenoids act in membrane disruption and alkaloids intercalate to cell wall or DNA [64]. 1,4Naphthalenedione from Holoptelea integrifolia [54], ethyl gallate from Caesalpinia spinosa [55] and corilagin from Arctostaphylos uva-ursi [75] were found to be active against beta-lactamase producing Staphylococcus aureus. Caffeic acid, ellagic acid, epigallocatechin-3gallate, quercetin isolated from Punica granatum were effective against beta- lactamase producing [76]. Metalo beta lactamase producing Stenotrophomonas maltophilia was inhibited by galangin a plant derived compound [77]. Although many plant extracts can contain toxic compounds that can give adverse effects if wrongly consumed [78-80]. Several research studies reported on consumption of alternative and complementary medicine (CAM) with allopathic medicine has not showed any adverse side effects. Most people also preferred to take CAM along with allopathic medicines as the effect of allopathic medicines were not satisfactory. Such combinational treatments with CAM and allopathic medicines requires further studies to assess, improvise and develop correct combinations to increase treatment options [81,82]. Also, isolation of specific compounds makes the compound specific to target with lesser side effects instead of whole plant extracts. Although more research is required to assess long term toxic effects of plant compounds more beneficial results are associated with the plant compounds if taken in correct doses $[80,83]$. It is also indicated that plants gave compounds that show positive synergism when combined with antibiotics [84-86]. Saklani et al. [87] reports several plant derived anti-infective and anticancer compounds and a total of 91 plant derived compounds were in the clinical trials in 2007. Koehn et al. [88] have reported that natural products from plant sources have higher number of chiral centers, oxygen atoms, hydrogen bond donors and acceptors. Such nature of chemical compounds benefits and enables to modify and develop analogues by changing the side chains to increase specificity and make modify the compound according to the target sites. This nature also facilitates deletion of functional groups that can be used to reduce the toxicity of the compound [89]. This approach is based on a hypothesis that the active compounds isolated from plants source could be safer than the ones extracted from plant species which shows minimal history of human use.

Previously, screening was done to isolate natural compounds against Escherichia coli harbouring NDM-1 from microbial sources [42], however the plant kingdom being the main source of drugs, remained unexplored. Plants have diverse chemical structure which can have several modes of action to inhibit MDR bacteria but until limited 
number of alternative compounds from plant sources have been reported. Chandar et al (2017) [90] screened 240 plant extracts which could be used further to develop formulations followed by isolation of active compounds. This study is the first large-scale screening for checking antibacterial activity of plant extracts against NDM-1 producing pathogenic organisms. In the study, ethanol extract from the leaves of 240 taxonomically diverse medicinal plant species representing 183 genera and 75 families were screened for antibacterial activity against NDM-1. The use of colistin was abandoned during 1970s due to nephrotoxicity [91] but re-emerged as lifesaving antibiotic to combat multidrug- resistant NDM-1 bacteria [10] and in the due course colistin resistance has also evolved [11-13]. Interestingly, reduction in MIC of colistin, meropenem and tetracycline was observed in all combinations of plant extracts [90]. Thus this combinational therapy could vastly help to reduce the antibiotic usage (colistin and carbapenems) and consumption in the long run which will in turn decrease the antibiotic resistance. Thus, alternative new drug development is in a continuous need for transformation of medicine in order to combat antimicrobial resistance. The safety of using most herbs with drugs is not well established. Some herbs are known to interact with pharmaceutical drugs, although most of this information comes from case reports rather than systematic investigations [92]. Because many herbs contain pharmacologically active compounds, some herbs may cause side effects through excessive biological effects. Unfortunately, the true frequency of side effects for most herbs is not known because most have not been tested in large clinical trials and because surveillance systems are much less extensive than those in place for pharmaceutical products [93]. This also calls for a strict regulation and policy to be formulated for use of herbal drugs in treating various common infections.

\section{Conclusion}

In the menace of antibiotic resistance, it is important to monitor the consumption of antibiotics and determine treatment ways to reduce the usage. Therefore, development of plant based compounds and combinational therapies using compounds may provide safer options for the community. Further research should focus on scrutinizing compounds from plants for a target and bioactivity based drug discovery. The government should also play an important role in promoting and supporting research in herbal medicine to evade the impending danger of no treatment alternate for deadly pathogens in our near future.

\section{Acknowledgement}

The authors are thankful to the Indian Council of Medical Research and Department of Biotechnology, Govt. of India.

\section{Funding}

The study was supported by extramural funding received from DBT's Twining project for NE (BCIL/NER-BPMC/2017/1030)

\section{References}

1. Woolhouse M, Waugh C, Perry MR, Nair H (2016) Global disease burden due to antibiotic resistance-state of the evidence. J Global Health 6: 1.

2. Harbarth S, Balkhy HH, Goossens H, Jarlier V, Kluytmans J, et al. (2015) Antimicrobial resistance: One world, one fight! Antimicrob Resist Infect Control 4: 49
3. Laxminarayan R, Duse A, Wattal C, Zaidi AKM, Wertheim HFL,et al. (2013) Antibiotic resistance-The need for global solutions. The Lan Infectious Dis 13: 1057-1098.

4. Laxminarayan R, Chaudhury RR (2016) Antibiotic Resistance in India: Drivers and Opportunities for Action. PLoS Med 13: e1001974.

5. Bryce A, Hay AD, Lane IF, Thornton HV, Wootton M, et al. (2016) Global prevalence of antibiotic resistance in paediatric urinary tract infections caused by Escherichia coli and association with routine use of antibiotics in primary care: systematic review and meta-analysis. BMJ 352: 1939.

6. World Health Organization (2017) Global priority list of antibioticresistant bacteria to guide research, discovery, and development of new antibiotics. Essential med health product.

7. Morton RS (1957) Side-Effects of Penicillin Treatment. Br J Vener Dis 33: 176-178.

8. Idsoe O, Guthe T, Willcox RR, Weck AL (1968) Nature and extent of penicillin side-reactions, with particular reference to fatalities from anaphylactic shock. Bull Wld Hlth Org 38: 159-188.

9. Yotsuji A, Hori JMR, Takashi Y, Saikawa I, Inoue M, et al. (1988) Mechanism of action of cephalosporins and resistance caused by decreased affinity for penicillin-binding proteins in Bacteroides fragilis. Antimicrob Agents Chemother 32: 1848-1853.

10. Kumarasamy KK, Toleman MA, Walsh TR, Bagaria J, Butt F, et al. (2010) Emergence of a new antibiotic resistance mechanism in India, Pakistan, and the UK: A molecular, biological, and epidemiological study. The Lan Infect Dis 10: 597-602.

11. Liu BT, Song FJ, Zou M, Hao ZH, Shan H (2017) Emergence of colistin resistance gene mcr-1 in cronobacter sakazakii producing ndm-9 and in Escherichia coli from the same animal. Antimicrob Agents Chemother 61: e01444-01516.

12. Elnahriry SS, Khalifa HO, Soliman AM, Ahmed AM, Hussein AM, et al. (2016) Emergence of plasmid-mediated colistin resistance gene mcr-1 in a clinical Escherichia coli isolate from Egypt. Antimicrob Agents Chemother 60: 3249-3250.

13. Yao X, Doi Y, Zeng L, Lv L, Liu JH (2016) Carbapenem-resistant and colistin-resistant Escherichia coli co-producing NDM-9 and MCR-1. The Lan Infect Dis 16: 288-289.

14. McKenna M (2013) Antibiotic resistance : The last resort. Nature 499: 394-396.

15. Carlet J, Jarlier V, Harbarth S, Voss A, Goossens H, et al. (2012) Ready for a World without Antibiotics? The Pensières Antibiotic Resistance Call to Action. Antimicrob Resist Infect Control 1: 11 .

16. Paterson DL, Bonomo RA (2017) Extended-spectrum $\beta$-lactamases: A clinical update. Clin Microbiol Rev 18: 657-686.

17. Pitout JD, Laupland KB (2008) Extended-spectrum $\beta$-lactamaseproducing Enterobacteriaceae: An emerging public-health concern. Lancet Infect Dis 8:159- 166

18. Karam G, Chastre J, Wilcox MK, Vincent JL (2016) Antibiotic strategies in the era of multidrug resistance. Crit Care 20: 136.

19. Soares GMS, Figueiredo LC, Faveri M, Cortelli SC, Duarte PM, et al. (2012) Mechanisms of action of systemic antibiotics used in periodontal treatment and mechanisms of bacterial resistance to these drugs. J Appl Oral Sci 20: 295-309.

20. Flokas ME, Detsis M, Alevizakos M, Mylonakis E (2016)Prevalence of ESBL-producing Enterobacteriaceae in paediatric urinary tract infections: A systematic review and meta-analysis. J Infect 73: 547-557.

21. Sharma M, Pathak S, Srivastava P (2013) Prevalence and Antibiogram of Extended Spectrum B-Lactamase (ESBL) Producing Gram Negative Bacilli and Further Molecular Characterization of ESBL Producing Escherichia Coli and Klebsiella Spp. J Clin Diagn Res囚10: 2173-2177.

22. Fernando MMPSC, Luke WANV, Miththinda JKND, Wickramasinghe RDSS, Sebastiampillai BS, et al. (2017) Extended spectrum beta lactamase producing organisms causing urinary tract infections in Sri Lanka and their antibiotic susceptibility pattern -A hospital based cross sectional study. BMC Infect Dis 17: 138. 
23. Bhattacharya D, Dey S, Kadam S, Kalal S, Jali S, et al. (2015) Isolation of NDM-1-producing multidrug-resistant Pseudomonas putida from a paediatric case of acute gastroenteritis, India. New Microbes New Infect 5: 5-9.

24. Joshi P R, Acharya M, Kakshapati T, Leungtongkam U, Thummeepak R, et al. (2017) Co-existence of blaOXA-23 and blaNDM-1 genes of Acinetobacter baumannii isolated from Nepal: Antimicrobial resistance and clinical significance. Antimicrob Resist Infect Control 6: 21.

25. Rahman M, Prasad KN, Pathak A, Pati BK, Singh A, et al. (2015) RmtC and RmtF 16S rRNA Methyltransferase in NDM-1-Producing Pseudomonas aeruginosa. Emerg Infect Dis 21: 2059-2062.

26. Gamal D, Martínez MF, Salem D, El-Defrawy I, Montes LÁ, et al. (2016) Carbapenem-resistant Klebsiella pneumoniae isolates from Egypt containing blaNDM-1 on IncR plasmids and its association with rmtF. Int J Infect Dis 43: 17-20.

27. Yong D, Toleman MA, Giske CG, Cho HS, Sundman K et al. (2009) Characterization of a new metallo- $\beta$-lactamase gene, bla NDM-1, and a novel erythromycin esterase gene carried on a unique genetic structure in Klebsiella pneumoniae sequence type 14 from India. Antimicrob Agents Chemother 53: 5046-5054.

28. Khan AU, Maryam L, Zarrilli R (2017) Structure, genetics and worldwide spread of new delhi metallo- $\beta$-lactamase (ndm): A threat to public health. BMC Microbiol 17: 101.

29. Bradford PA (2001) Extended-Spectrum $\beta$-Lactamases in the 21st Century: Characterization, Epidemiology, and Detection of This Important Resistance Threat. Clin Microbiol Rev 14: 933-951.

30. King, DT, Worrall LJ, Gruninger RJ, Strynadka NCJ (2012) New Delhi metallo- $\beta$-lactamase: Structural insights into $\beta$-lactam recognition and inhibition. J Am Chem Soc 134: 11362-11365.

31. Ventola LC (2015) The antibiotic resistance crisis part 2: Management strategies and new agents. PT 40: 344-352.

32. Patzer JA, Timothy RW, Weeks J, Anowska DD, Toleman MA (2009) Emergence and persistence of integron structures harbouring VIM genes in the Children's Memorial Health Institute, Warsaw, Poland, 1998-2006. J Antimicro Chemo 63: 269-273.

33. Overdevest I, Willemsen I, Rijnsburger M, Eustace A, Xu L et al. (2011) Extended-spectrum $\beta$-lactamase genes of escherichia coli in chicken meat and humans, the Netherlands. Emerg Infect Dis 17: 1216-1222.

34. Naas T, Ergani A, Carre"r A, Nordmann P (2011) Real-Time pcr for detection of ndm-1 carbapenemase genes from spiked stool samples. Antimicrob Agents Chemother 55: 4038-4043.

35. Nordmann P, Poirel L, Carrer A, Toleman MA, Walsh TR (2011) How to detect ndm-1 producers. Journal of clinical microbiology 49: 718-721.

36. Qi J, Du Y, Zhu X, Bai H, Luo Y, (2012) A loop-mediated isothermal amplification method for rapid detection of ndm-1gene. Microb Drug Resist 4: 359-363.

37. Yang Z, Wei L, Qian C, Niu W, Li H, et al. (2014) Prevalence and detection of Stenotrophomonas maltophilia carrying metallo- $\beta$-lactamase blaL1 in Beijing, China. Front Microbiol 5: 692.

38. Huang JM, Henihan G, Macdonald D, Michalowski A, Templeton K, et al. (2015) Rapid electrochemical detection of new delhi metallo-betalactamase genes to enable point-of-care testing of carbapenem-resistant enterobacteriaceae. Anal Chem. 87: 7738-7745.

39. Pasteran F, Gonzalez LJ, Albornoz E, Bahr G, Vila AJ, et al. (2016) Triton Hodge Test: Improved protocol for modified hodge test for enhanced detection of ndm and other carbapenemase producers. J Clin Microbiol 54: 640-649.

40. Ke Y, Wang Y, Wang Z, Du X, Huang L, et al. (2013) Sensitive and rapid detection of blaNDM-1 in clinical samples by isothermal cross-priming amplification. J Microbiol Methods 95: 215-217.

41. Livermore DM, Mushtaq S, Nguyen T, Warner M (2011) Strategies to overcome extended-spectrum $\beta$-lactamases (ESBLs) and AmpC $\beta$ lactamases in shigellae. Int J Antimicrob Agents 37: 405-409.
42. King AM, Reid-Yu SA, Wang W, King DT, Pascale GD, et al. (2014) Aspergillomarasmine A overcomes metallo- $\beta$-lactamase antibiotic resistance. Nature 510: 503-506.

43. Chiou J, Wan S, Chan KF, So PK, He D, et al. (2015) Ebselen as a potent covalent inhibitor for New Delhi Metallo- $\beta$-lactamase (NDM-1). Chem Commun 51: 95432-9546.

44. Guo Y, Wang J, Niu G, Shui W, Sun Y, et al. (2011) A structural view of the antibiotic degradation enzyme NDM-1 from a superbug. Protein Cell 2: 384-394.

45. Thomas PW, Michael C, Brodbelt JS, Fast W (2014) Covalent Inhibition of New Delhi Metallo- $\beta$-Lactamase-1 (NDM-1) by Cefaclor. ChemBio Chem 15: 2541-2548.

46. Zhang YL, Yang KW, Zhou YJ, Lacuran AE, Oelschlaeger P, et al. (2014) Diaryl-substituted azolylthioacetamides: inhibitor discovery of new delhi metallo- $\beta$-lactamase-1 (NDM-1). ChemMed Chem 1: 2445-2448.

47. Cheng AA, Ding H, Lu TK (2014) Enhanced killing of antibiotic-resistant bacteria enabled by massively parallel combinatorial genetics. PNAS 111: 12462-12467.

48. Citorik RJ, Mimee M, Lu TK (2014) Sequence-specific antimicrobials using efficiently delivered RNA-guided nucleases. Nature Biotech 32: 1141-1145.

49. Khan U, Abid A, Danishuddin, Srivastava G, Sharma A (2017) Potential inhibitors designed against NDM-1 type metallo- $\beta$-lactamases: An attempt to enhance efficacies of antibiotics against multi-drug-resistant bacteria. Scien Rep 7: 9207.

50. Hancock RE (2005) Mechanisms of action of newer antibiotics for Grampositive pathogens. Lancet Infect Dis 5: 209-218.

51. World Health Organization (1998) Guidelines for the appropriate use of herbal medicines. Pp. 1-88.

52. Goswami A, Barooah PK, Sandhu JS (2002) Prospect of herbal drugs in the age of globalization- Indian scenario. J Scien Indust Res 61: 423-431.

53. Brantner A, Males Z, Pepeljnjak S, Antolic A (1996) Antimicrobial activity of Paliurus spina-christi Mill (Christ's thorn). J Ethnopharmacol 52: 119-122.

54. Croft KD (1998) The chemistry and biological effects of flavonoids and phenolic acids. Ann N Y Acad Sci 854: 435-442.

55. Cushnie TPT, Lamb AJ (2005) Antimicrobial activity of flavonoids. Int J Antimicrob Agents 26: 343-356.

56. Maddox CE, Laur LM (2010) Antibacterial activity of phenolic compounds against the phytopathogen Xylella fastidiosa. Curr Microbiol 60: 53-58.

57. Pimiä RP, Nohynek L, Schmidlin $\mathrm{SH}$, Kähkönen $\mathrm{M}$, Heinonen $\mathrm{M}$, et al. (2005) Berry phenolics selectively inhibit the growth of intestinal pathogens. J Appl Microbiol 98: 991-1000.

58. Mathabe MC, Hussein AA, Nikolova RV, Basson AE, Meyer JJ, et al. (2008) Antibacterial activities and cytotoxicity of terpenoids isolated from Spirostachys Africana. J Ethnopharmacol 116: 194-197.

59. Trombetta D, Castelli F, Sarpietro MG, Venuti V, Cristani M, et al. (2005) mechanisms of antibacterial action of three monoterpenes. Antimicrob Agents Chemother 49: 2474-2478.

60. Alicia SR, Adriana D, Adriana G, Susana G, Manuel A, et al. (2003) Antibacterial activity of lactose-binding lectins from Bufo arenarum skin. Biocell 27: 37-46.

61. Charungchitrak C, Petsom A, Sangvanich P, Karnchanatat A (2011) Antifungal and antibacterial activities of lectin from the seeds of Archidendron jiringa Nielsen. Food Chem 126: 1025-1032.

62. Jennsen H, Hamill P, Hancock REW (2006) Peptide Antimicrobial Agents. Clin Microbiol Rev 19: 491-511.

63. Bahar AA, Ren D (2013) Antimicrobial Peptides. Pharmaceuticals (Basel) 6: 1543-1575.

64. Cowan MM (1999) Plant products as antimicrobial agents. Clin Microbiol Rev 12: 564-582.

65. Kuete V (2010) Potential of Cameroonian plants and derived products against microbial infections: A review. Planta Med 76: 1479-1491. 
Citation: Chandar B, Pati S and Bhattacharya D (2018) An Overview of New Delhi Metallo-Beta Lactamase-1 and Extended Spectrum Beta Lactamase Producing Bacteria: Need for an Alternate. J Antimicrob Agents 4: 155. doi:10.4172/2472-1212.1000155

Page 6 of 6

66. Araujo MG, Hilario F, Nogueira LG, Vilegas W, Santos LC, et al. (2011) Chemical constituents of the methanolic extract of leaves of Leiothrix spiralis Ruhland and their antimicrobial activity. Molecules 16: 10479-10490.

67. Limaa B, Sanchez M, Agüeroa MB, Tapiaa A, Palermo JA, et al. (2015) Antibacterial activity of extracts and compounds isolated from the andean medicinal plant Azorella cryptantha (Clos) Reiche, Apiaceae. Indust Crops Prod 64: 152-157.

68. Chew YL, Chan EWL, Tan PL, Lim YY, Stanslas J, et al. (2011) Assessment of phytochemical content, polyphenolic composition, antioxidant and antibacterial activities of Leguminosae medicinal plants in Peninsular Malaysia. BMC Complement Alternative Med 2: 12.

69. Pandey AK, Singh P, Tripathi NN (2014) Chemistry and bioactivities of essential oils of some Ocimum species: an overview. Asian Paci J Trop Biomed 4: 682-694.

70. Zengin H, Baysal AH (2014) Antibacterial and antioxidant activity of essential oil terpenes against pathogenic and spoilage-forming bacteria and cell structure-activity relationships evaluated by sem microscopy. Molecules 19: 17773-17798.

71. Bandyopadhyay S, Patra PH, Mahanti A, Mondal DK, Dandapat P, et al. (2013) Potential antibacterial activity of berberine against multi drug resistant enterovirulent Escherichia coli isolated from yaks (Poephagus grunniens) with haemorrhagic diarrhea. Asian Pac J Trop Med 6: 315-319

72. Hou AJ, Liu YZ, Yang H, Lin ZW, Sun HD (2000) Hydrolyzable tannins and related polyphenols from eucalyptus globulus. J Asian Nat Prod Res 2: 205-212.

73. Christelle MA, Hausman JF, Guerriero G (2016) Cannabis Sativa: the plant of the thousand and one molecules. Front Plant Sci 7: 19.

74. Thakur P, Chawla R, Chakotiya AS, Tanwar A, Goel R, et al. (2015) Camellia sinensis ameliorates the efficacy of last line antibiotics against carbapenem resistant Escherichia coli. Phytother Res. 30: 314-322.

75. Shimizu M, Shiota S, Mizushima T, Ito H, Hatano T, et al. (2001) Marked potentiation of activity of $\beta$-lactams against methicillin-resistant Staphylococcus aureus by Corilagin. Antimicrob Agents Chemother 45: 3198-3201.

76. Dey D, Ray R, Hazra B (2015) Antimicrobial activity of pomegranate fruit constituents against drug-resistant Mycobacterium tuberculosis and $\beta$ lactamase producing Klebsiella pneumonia. Pharm Biol 53: 1-7.

77. Denny BJ, Lambert PA, West PWJ (2002) The flavonoid galangin inhibits the L1 metallo- $\beta$-lactamase from Stenotrophomonas maltophilia. FEMS Microb Lett 208: 21-24.

78. Quattrocchi U (2012) CRC World dictionary of medicinal and poisonous plants: common names. CRC Press 5: 3960.
79. Nithaniyal S, Vassou SL, Poovitha S, Raju B, Parani M (2017) Identification of species adulteration in traded medicinal plant raw drugs using DNA barcoding. Genome 60: 139-146.

80. Lavecchia T, Rea G, Antonacci A, Giardi MT (2013) Healthy and adverse effects of plant-derived functional metabolites: The need of revealing their content and bioactivity in a complex food matrix. Crit Rev Food Sci Nutr 53: 198-213.

81. Singh S, Waman AA, Bohra P, Gautam RK, Roy SD (2016) Conservation and sustainable utilization of horticultural biodiversity in tropical Andaman and Nicobar Islands, India. Genet Resour Crop Evol 63: 1431-1445.

82. Dale LC, Gotay CC (2012) The relationship between complementary and alternative medicine use and breast cancer early detection: A critical review. Evid-Based Complem Alternat Med 2012: 1-10.

83. Hollman PCH (2001) Evidence for health benefits of plant phenols: Local or systemic effects? J Sci Food Agric 81: 842-852.

84. Berdy J. (2012) Thoughts and facts about antibiotics: Where we are now and where we are heading. J Antibiot 65: 385-395.

85. Bollenbach $\mathrm{T}$ (2015) Antimicrobial interactions: Mechanisms and implications for drug discovery and resistance evolution. Curr Opin Microbiol 27: 1-9.

86. Savoia D (2012) Plant-derived antimicrobial compounds: Alternatives to antibiotics. Future Microbiol 7: 979-990.

87. Saklani A, Kutty SK (2008) Plant-derived compounds in clinical trials. Drug Discov Today 13: 161-171.

88. Koehn FE, Carter GT (2005) The evolving role of natural products in drug discovery. Nat Rev Drug Discov 4: 207-220.

89. Katiyar C, Gupta A, Kanjilal S, Katiyar S (2012) Drug discovery from plant sources: An integrated approach. Ayu 33: 10-19.

90. Chandar B, Poovitha S, Ilango K, Kumar MR, Parani M (2017) Inhibition of New Delhi Metallo- $\beta$-Lactamase 1 (NDM-1) producing Escherichia coli IR- 6 by selected plant extracts and their synergistic actions with antibiotics. Front Microbiol 8: 1580.

91. Ortwine JK, Sutton JD, Kaye KS, Pogue JM (2015) Strategies for the safe use of colistin. Expert Rev Anti Infect Ther 13: 1237-1247.

92. Smet PAD (2002) Herbal remedies. N Engl J Med 347: 2046-2056.

93. Bent S (2008) Herbal medicine in the United States: Review of efficacy, safety, and regulation: grand rounds at University of California, San Francisco Medical Centre. J Gen Int Med 23: 854-859. 